\title{
INFLUENCE OF DEMOGRAPHIC FACTORS ON STANDARDISED RATE RATIO OF AGE-ADJUSTED MORTALITY RATES OF MEN IN COMPARISON WITH WOMEN CAUSED BY NEOPLASMS AND CIRCULATORY DISEASES IN SLOVAK REGIONS DURING 1996-2013
}

\author{
Beáta Gavurová1, Samuel Koróny², Michal Šoltés ${ }^{1}$ \\ ${ }^{1}$ Faculty of Economics, Technical University of Košice, Košice, Slovak Republic \\ ${ }^{2}$ Research and Innovation Centre, Faculty of Economics, Matej Bel University, Banská Bystrica, Slovak Republic
}

\section{SUMMARY}

Aim: The aim of our study was to find statistical associations including trends of standardised rate ratio of age-adjusted mortality rates for the male population as compared to the female population, in relation to available demographic factors (Chapter II - neoplasms vs. Chapter IX - Diseases of the circulatory system, Slovak region and calendar year of death).

Methods: Dataset of individual cases of death in Slovakia with some demographic factors during 1996-2013 were provided by Slovak National Health Information Center. We used regression and correlation analyses, as well as analyses of variance and covariance along with descriptive statistics.

Results: The standardised rate ratio of age adjusted mortality rates of men versus age-adjusted mortality rates of women differs between Chapter II and Chapter IX (mean 2.08 vs. 1.35, $p<0.001)$. There are also significant differences of standardised rate ratio among regions $(p<0.05)$. Trends show that the standardised rate ratio has significant regional decline for Chapter II: Košice $(p<0.01)$, Trenčín $(p<0.001)$ and Žilina $(p<0.05)$ whereas in Chapter IX Žilina region $(p<0.01)$ is implicated. In other Slovak regions standardised rate ratio stagnates.

Conclusions: Standardised rate ratios of age-adjusted mortality rates for the male population compared to the female population are significantly dependent on chapter, sex and region. Standardised rate ratios either decline or stagnate.

Key words: mortality, diseases of the circulatory system, neoplasms, statistical data analysis

Address for correspondence: S. Koróny, Research and Innovation Centre, Faculty of Economics, Matej Bel University, Cesta na amfiteáter 1 , 97401 Banská Bystrica, Slovak Republic. E-mail: samuel.korony@umb.sk

https://doi.org/10.21101/cejph.a5057

\section{INTRODUCTION}

Many foreign research studies deal with examining the basic biosocial characteristics (age, sex, marital and social status, etc.) because of the revealing of priority classification line when considering the development of mortality and morbidity diagnoses, resp. groups of diagnoses. Gender as a basic classificatory character in many research studies allows deeper study of other related socioeconomic determinants of mortality development of the region, standard of living and its impact on population health, risk impact, environmental factors, etc. For example, the study by Mikkola et al. (1) that shows an increase in mortality from cardiovascular disease in men of younger age opposite to women, in women it increases sharply after 60 years of age. The study does not specify or examine why are so significant age differences registered. Reason is multi-dimensional impacts associated with the heterogeneity of the socio-economic conditions in the regions of the country.
A research study by Roth et al. (2) dealt with the deeper research on regional disparities in the development of cardiovascular mortality in the years 1990-2013. The results of the analysis declare the fact that in the long term is a clear decline in cardiovascular mortality, but also the diagnosis is shifting increasingly to the lower ages, which is negative phenomena in the context of the set of prevention programs. The authors highlight the importance of studying the development of mortality differentiated not only by age and sex, but also regions, because there is a large variation in mortality between regions and within them. These facts raise logical place to appeal for the creation of overall regional health plans, which would reflect the current state of health of the population of the region and all its determinants which acts on it. This would support the creation of regional platforms and the comparative production of specific health policies.

Regional disparities in the development of mortality at a higher geographical level (countries and continents) were examined by 
experts in the study by Naghavi et al. (3), which aimed at examining epidemiological differences in the evolution of mortality in 188 countries between 1990 and 2013. The increase in agestandardised mortality rates in some countries indicates a serious failure in health policy in selected countries and regions that promote many research teams to examine deeper and detect causes.

Indian study of research experts Gupta et al. (4) confirms the existence of significant regional differences in risk factors. At the macro level significant regional differences in mortality due to cardiovascular disease were analysed and confirmed. The authors of the study appeal on the need for the implementation of further analysis of the different risk factors that cause different mortality of cardiovascular diseases to compare the results between regions to one another within the same country. Also, Moran et al. (5) explore the deep difference in mortality between countries (21 countries were surveyed), and came to the conclusion that in most regions of the world, particularly in high-income world, the age-standardised mortality from ischemic heart disease declines since 1980. In the countries of Eastern Europe, Central Asia and South Asia, where high age-standardised mortality from ischemic heart disease have been recorded the authors appeal on the need of active prevention and permanent monitoring of risk factors. They also highlight the importance of the research of unique behavioural and environmental determinants of increased mortality from ischemic heart disease.

There are many similar research studies (3, 5-8), their importance results from the detection of context and regional disparities in mortality in specific groups of diseases, in order to subsequently detect all determinants that cause these disparities and thus contribute to the deepening of inequalities in health between regions and between countries. European Union programs clearly put pressure to eliminate these inequalities in health and to the development of active policies and international benchmarks that would support improving the health of populations worldwide (9-11).

Despite the availability of a wide range of research studies addressing the issue of the impact of socioeconomic factors on mortality, currently it is very difficult to find recommendations on how to proceed in developing the concept of national health policy, the creation of regional health plans or prevention programs $(12,13)$. It can result from the significant heterogeneity of health systems in individual countries, lower availability of their database, as well as the rate of adaptability and acceptability of the results of research teams for health policy of the country (14, 15). Ones of the forms of elimination of low rates of knowledge dissemination between countries in the field of effective prevention programs are the active cooperation between countries in the field of public health, sharing research results and improving data base that provides for national as well as international benchmarking in this area (16-18).

In Slovak Republic, more than three fourths of deaths are caused by diseases either from Chapter II (ICD - International Statistical Classification of Diseases and Related Health Problems, neoplasms, C00-D48,) or from Chapter IX (circulatory system diseases, I00-I99). The corresponding proportions during 1996-2013 were $22.7 \%$ and $54.0 \%$ (together $76.7 \%$ ). Main objective of our paper is to find statistical associations including trends of standardised rate ratio of age-adjusted mortality rates for population of men compared to population of women in relation with available demographic factors (chapter, region and calendar year of death).

\section{MATERIALS AND METHODS}

Slovak National Health Information Center kindly gave us data about individual cases of deaths in Slovakia with some demographic factors during 1996-2013. Aggregated death counts according to chapter, sex region and calendar year of death were then adjusted by direct standardisation according to age and sex for purpose of comparisons. Reference population was EU population in standard 5-year age intervals for both sexes. But adjusted rate has meaning only when compared with a similarly adjusted rate. Its value means little itself (19). Therefore, we used the ratio of age-adjusted mortality rates of men versus age-adjusted mortality rates of women. It is called standardised rate ratio (SRR) (20).

Beside basic descriptive statistics we used regression and correlation analyses and analysis of variance (ANOVA) and analysis of covariance (ANCOVA). Regression and correlation analyses were used for trend estimations of standardised rate ratios in separate regions during 1996-2013. Analysis of covariance was used for comparisons based on two categorical factors (chapter and region) and one continuous variable (calendar year of death). We have found ANCOVA useful in testing of regression (slope) parameters equality. One of assumptions of ANOVA and ANCOVA is homogeneity of variances in compared groups (tested by Levene's homogeneity-of-variance test). In our case it is not fulfilled. So we used nonparametric Kruskal-Wallis test with stepwise stepdown multiple comparisons for attainment of homogenous subgroups. Another assumption is that each group is an independent random sample from a normal population. ANOVA is robust to departures from normality but the data should be symmetric. All statistical reports and graphs were made in statistical software IBM SPSS version 19.

\section{RESULTS}

Let us present results of analyses for standardised rate ratio (SRR) of adjusted mortality rates of men versus adjusted mortality rates of women. We can see from Table 1 that maximum value of standardised rate ratio (1.595) in Chapter IX is smaller than is minimum value of standardised rate ratio (1.616) in Chapter II. So ranges of standardised rate ratio values in chapters did not overlap at all. It means significant difference $(\mathrm{p}<0.001)$ in case of so many values. Now we can make conclusions about meaning of SRR values. Maximum value in Chapter II is 2.467. It means that age-adjusted mortality rate of men in comparison with ageadjusted mortality rate of women is by $146.7 \%$ larger. In case of minimum value, it is larger by $61.6 \%$. In Chapter IX range of relative difference between men and women of SRR values is smaller (from $18.6 \%$ to $59.5 \%$ )

We present here also ten extreme (the largest and the smallest) values of SRR according to chapter, region and year of death. In tables and in graphs we use common abbreviations of Slovak regions: BC (Banská Bystrica), BL (Bratislava), KE (Košice), NI (Nitra), PV (Prešov), TA (Trnava), TC (Trenčín) and ZA (Žilina).

Two regions are remarkable at first sight in Chapter II (Table 2). Region Prešov occurs in seven cases of ten largest values. On contrary Bratislava region is by far the best region. All 10 smallest SRR values belong to Bratislava. In Chapter IX the situation is not 
Table 1. Statistical parameters of standardised rate ratio by chapter

\begin{tabular}{|l|c|c|c|c|c|c|}
\hline Chapter & N & Mean & Median & SD & Minimum & Maximum \\
\hline II-neoplasms & 144 & 2.077 & 2.069 & 0.1891 & 1.616 & 2.467 \\
\hline IX-diseases of the circulatory system & 144 & 1.354 & 1.352 & 0.0577 & 1.186 & 1.595 \\
\hline
\end{tabular}

so clear. Extreme values are distributed more uniformly among regions. No region prevails as in case of Chapter II.

Now we can use analysis of covariance to test influence of chapter, region and calendar year of death on standardised rate ratio. Levene's homogeneity of variance test is significant $(\mathrm{p}<0.001)$. That is why we use nonparametric Kruskal-Wallis test.

From ANCOVA table it is clear that there are significant differences of SRR between chapters $(p<0.001)$ (Table 3). Also there are significant differences of SRR among regions $(\mathrm{p}=0.016)$ and among years $(p<0.001)$. What else all interaction terms - chapter* region $(\mathrm{p}<0.001)$, chapter* year $(\mathrm{p}<0.001)$ and region * year $(p=0.017)$ are significant. In our case the effect of region on SRR is different in Chapter II in comparison with Chapter IX. Second significant interaction term tells us that effect of year on SRR is dependent on chapter. And last, effect of calendar year of death on SRR is dependent on region. An assumption underlying the correct usage of ANCOVA is that the regression slopes associated with the categorical factors are equal (21). In our case this assumption is violated. So we split reports by regions.

Histogram of standardised rate ratio by chapter presents difference between standardised rate ratios of Chapter II and of Chapter IX (Fig. 1). Difference is clear not only in parameters of location and scale but also in shape of empirical distributions.
In case of standardised rate ratio by regions in Chapter II it is not so clear. In Figure 2 are depicted corresponding boxplots by region. We can see for example downward positive shift in values of standardised rate ratio in Bratislava region in comparison with all other Slovak regions. In case of Chapter IX (Fig. 3) we are not able to say any reliable conclusions about differences among Slovak regions.

Because of non-homogeneity of variance, we used KruskalWallis test to test equality of regions based on standardised rate ratio values. By stepwise stepdown multiple comparisons, we found homogenous subsets of regions.

We see that in case of Chapter II three of four homogenous subsets of Slovak regions overlap (Table 4). Each cell shows the sample average rank of SRR. The first subset of Bratislava is distinct. Bratislava is relatively the best region with the smallest standardised rate ratio values. The worst region is Prešov but it is not statistically worse than are other two regions - Banská Bystrica and Žilina.

Stepwise stepdown test confirms situation of standardised rate ratio in Chapter IX which we presented in boxplots of regions. There are only two homogenous subsets that really overlap (Table 5). Relatively the best region with smallest standardised rate ratio values is Trnava but it is not statistically better than are other five

Table 2. Extreme values of standardised rate ratio by chapter, by region and by year of death

\begin{tabular}{|c|c|c|c|c|c|c|c|}
\hline \multicolumn{4}{|c|}{ Chapter II } & \multicolumn{4}{|c|}{ Chapter IX } \\
\hline Region & Year & SRR & Extremes & Region & Year & SRR & Extremes \\
\hline PV & 2002 & 2.467 & Max. & ZA & 2001 & 1.595 & Max. \\
\hline ZA & 2002 & 2.459 & Max. & $\mathrm{BL}$ & 1996 & 1.507 & Max. \\
\hline PV & 1996 & 2.456 & Max. & $\mathrm{BC}$ & 2007 & 1.492 & Max. \\
\hline PV & 1998 & 2.419 & Max. & ZA & 1996 & 1.481 & Max. \\
\hline PV & 2013 & 2.406 & Max. & $\mathrm{TC}$ & 2003 & 1.475 & Max. \\
\hline $\mathrm{BC}$ & 1998 & 2.397 & Max. & TC & 1997 & 1.458 & Max. \\
\hline $\mathrm{KE}$ & 1999 & 2.396 & Max. & $\mathrm{NI}$ & 2008 & 1.454 & Max. \\
\hline PV & 2010 & 2.395 & Max. & ZA & 2002 & 1.439 & Max. \\
\hline PV & 1999 & 2.395 & Max. & ZA & 2003 & 1.435 & Max. \\
\hline PV & 2005 & 2.377 & Max. & $\mathrm{TC}$ & 2004 & 1.430 & Max. \\
\hline $\mathrm{BL}$ & 1997 & 1.750 & Min. & PV & 2001 & 1.274 & Min. \\
\hline $\mathrm{BL}$ & 2002 & 1.739 & Min. & $B \mathrm{~L}$ & 2003 & 1.272 & Min. \\
\hline $\mathrm{BL}$ & 1996 & 1.737 & Min. & TC & 2012 & 1.265 & Min. \\
\hline $\mathrm{BL}$ & 2008 & 1.712 & Min. & $\mathrm{BL}$ & 1999 & 1.261 & Min. \\
\hline $\mathrm{BL}$ & 2012 & 1.690 & Min. & KE & 2001 & 1.255 & Min. \\
\hline $\mathrm{BL}$ & 2010 & 1.674 & Min. & TA & 2013 & 1.254 & Min. \\
\hline $\mathrm{BL}$ & 2013 & 1.667 & Min. & TA & 2000 & 1.251 & Min. \\
\hline $\mathrm{BL}$ & 2006 & 1.665 & Min. & PV & 2005 & 1.231 & Min. \\
\hline $\mathrm{BL}$ & 2001 & 1.651 & Min. & $\mathrm{NI}$ & 2013 & 1.229 & Min. \\
\hline $\mathrm{BL}$ & 1999 & 1.616 & Min. & PV & 2011 & 1.186 & Min. \\
\hline
\end{tabular}


Table 3. ANCOVA table of standardised rate ratio by chapter, by region and by year

\begin{tabular}{|l|c|c|c|c|c|}
\hline Source & $\begin{array}{c}\text { Type III } \\
\text { Sum of squares }\end{array}$ & Degrees of freedom & Mean square & F & p-value \\
\hline Corrected model & 41.115 & 24 & 1.713 & 213.338 & $<0.001$ \\
\hline Intercept & 0.292 & 1 & 0.292 & 36.338 & $<0.001$ \\
\hline Chapter & 0.097 & 1 & 0.097 & 12.128 & $<0.001$ \\
\hline Region & 0.141 & 7 & 0.020 & 2.513 & 0.016 \\
\hline Year & 0.216 & 1 & 0.216 & 26.907 & $<0.001$ \\
\hline Chapter* region & 1.354 & 7 & 0.193 & 24.081 & $<0.001$ \\
\hline Chapter*year & 0.088 & 1 & 0.088 & 10.926 & $<0.001$ \\
\hline Region*year & 0.140 & 7 & 0.020 & 2.493 & 0.017 \\
\hline Error & 2.112 & 263 & 0.008 & & \\
\hline Total & 890.772 & 288 & & & \\
\hline Corrected total & 43.227 & 287 & & & \\
\hline
\end{tabular}

regions - Bratislava, Prešov, Trenčín, Nitra and Košice. The worst region is Žilina and it is not different from all other regions with exception of Trnava.

Now we can test possible trends of standardised rate ratio in separate Slovak regions and in both chapters. We present here

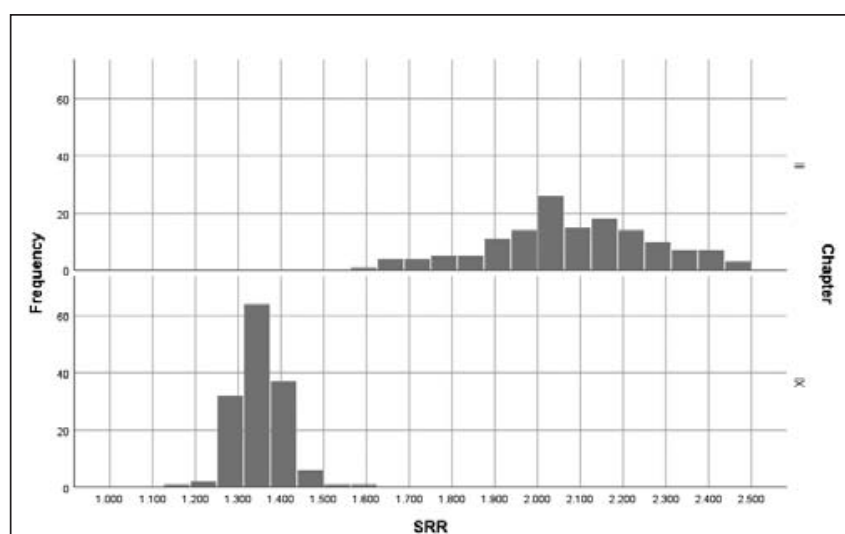

Fig. 1. Histogram of standardised rate ratio by chapter.

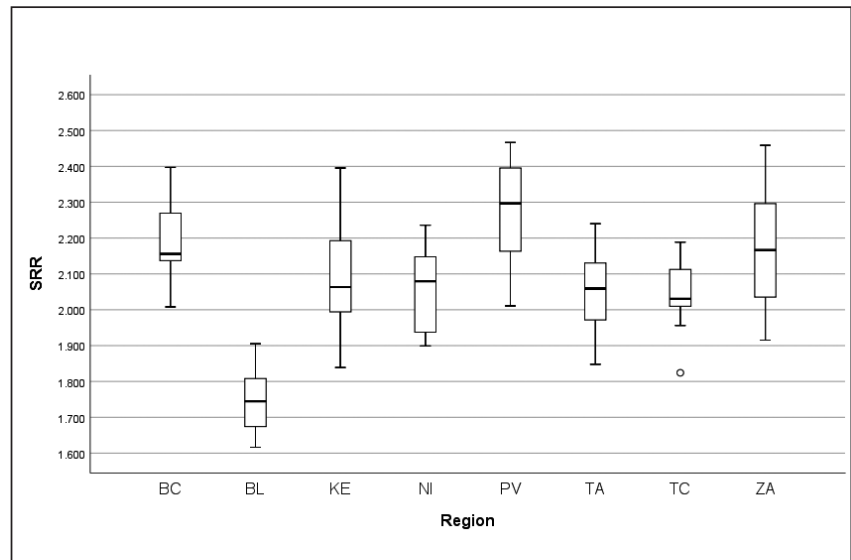

Fig. 2. Boxplot of standardised rate ratio by regions in Chapter II. robust Spearman correlation coefficients of time dependence of SRR values. Results are presented in Table 6. From sixteen Spearman correlation coefficients four ones are significant.

Standardised rate ratio of age-adjusted mortality rates between men and women declines significantly in Chapter II in regions Košice (coefficient of determination $=39.4 \%, \mathrm{p}<0.01$ ), Trenčín (see Fig. 4, coefficient of determination $=58.5 \%, p<0.001$ ) and Žilina (coefficient of determination $=32.3 \%, \mathrm{p}<0.05$ ) In Chapter IX it is the case of Žilina region (see Fig. 5, coefficient of determination $=32.4 \%$ ), $\mathrm{p}<0.01$ ). In other Slovak regions standardised rate ratio stagnates.

\section{DISCUSSION}

We wanted to find some statistical associations including possible trends of standardised rate ratio of age-adjusted mortality rates between men and women in relation with available demographic factors (Chapter II and Chapter IX of International Statistical Classification of Diseases, region and calendar year of death) during 1996-2013 in Slovak regions.

Standardised rate ratio of age-adjusted mortality rates between men and women is different between chapters $(\mathrm{p}<0.001)$. Also

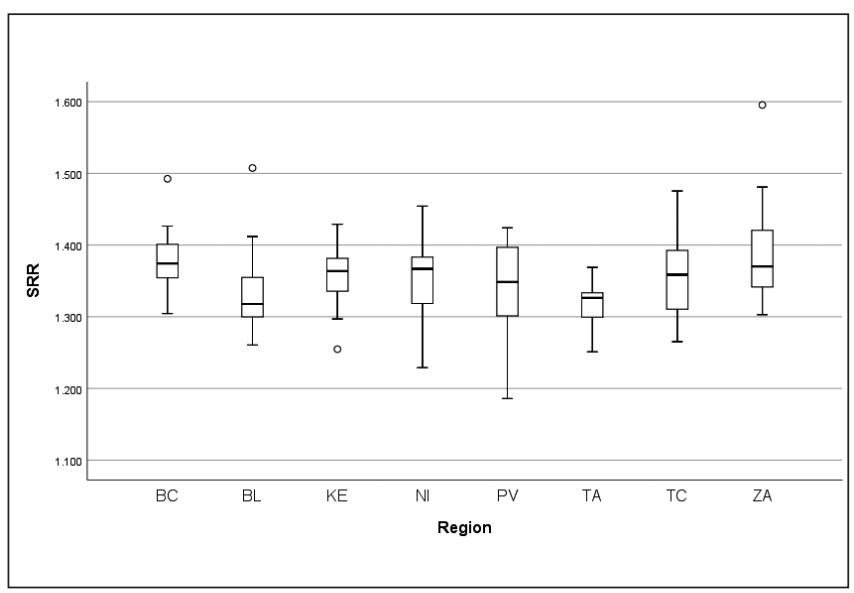

Fig. 3. Boxplot of standardised rate ratio by regions in Chapter IX. 
Table 4. Homogenous subsets of regions based on standardised rate ratio in Chapter II

\begin{tabular}{|l|l|c|c|c|c|}
\hline \multicolumn{2}{|c|}{} & \multicolumn{4}{|c|}{ Subset } \\
\cline { 2 - 6 } \multicolumn{1}{|c|}{} & $\mathbf{1}$ & $\mathbf{2}$ & $\mathbf{3}$ & $\mathbf{4}$ \\
\hline \multirow{5}{*}{ Region } & BL & 10.111 & & & \\
\cline { 2 - 6 } & TC & & 65.444 & & \\
\cline { 2 - 6 } & TA & & 65.444 & & \\
\cline { 2 - 6 } & NI & & 65.667 & & \\
\cline { 2 - 6 } & KE & & 71.500 & 71.500 & \\
\cline { 2 - 6 } & ZA & & 88.667 & 88.667 & 88.667 \\
\cline { 2 - 6 } & BC & & & 98.778 & 98.778 \\
\hline & PV & & & & 114.389 \\
\hline Test statistic & - & 4.790 & 4.389 & 5.508 \\
\hline Adjusted p-value & - & 0.447 & 0.270 & 0.161 \\
\hline
\end{tabular}

Table 5. Homogenous subsets of regions based on standardised rate ratio in Chapter IX

\begin{tabular}{|l|l|c|c|}
\hline \multicolumn{2}{|c|}{} & \multicolumn{2}{|c|}{ Subset } \\
\cline { 2 - 4 } \multicolumn{1}{|c|}{} & TA & 40.389 & $\mathbf{2}$ \\
\hline \multirow{5}{*}{ Region } & BL & 55.111 & \\
\cline { 2 - 4 } & PV & 67.000 & 55.111 \\
\cline { 2 - 4 } & TC & 75.778 & 67.000 \\
\cline { 2 - 4 } & NI & 76.833 & 75.778 \\
\cline { 2 - 4 } & KE & 77.500 & 76.833 \\
\cline { 2 - 4 } & BC & & 77.500 \\
\cline { 2 - 4 } & ZA & & 93.222 \\
\hline Test statistic & 11.052 & 94.167 \\
\hline Adjusted p-value & 0.067 & 11.053 \\
\hline
\end{tabular}

Table 6. Spearman correlation coefficients of standardised rates ratio and time by Slovak regions

\begin{tabular}{|l|c|c|}
\hline Region & Chapter II & Chapter IX \\
\hline Banská Bystrica & -0.304 & -0.189 \\
\hline Bratislava & -0.075 & 0.011 \\
\hline Košice & $-0.692^{* *}$ & 0.243 \\
\hline Nitra & -0.307 & -0.189 \\
\hline Prešov & -0.329 & 0.024 \\
\hline Trnava & 0.199 & 0.148 \\
\hline Trenčín & $-0.732^{* * *}$ & -0.290 \\
\hline Žilina & $-0.540^{*}$ & $-0.635^{* *}$ \\
\hline
\end{tabular}

${ }^{*} p<0.05,{ }^{* \star} p<0.01,{ }^{* \star *} p<0.001$

there are significant differences of SRR among regions $(\mathrm{p}<0.05)$ and among years $(\mathrm{p}<0.001)$.

Standardised rate ratio declines significantly in Chapter II in regions Košice $(p<0.01)$, Trenčín $(p<0.001)$ and Žilina $(p<0.05)$. In Chapter IX it is the case of Žilina region $(\mathrm{p}<0.01)$.

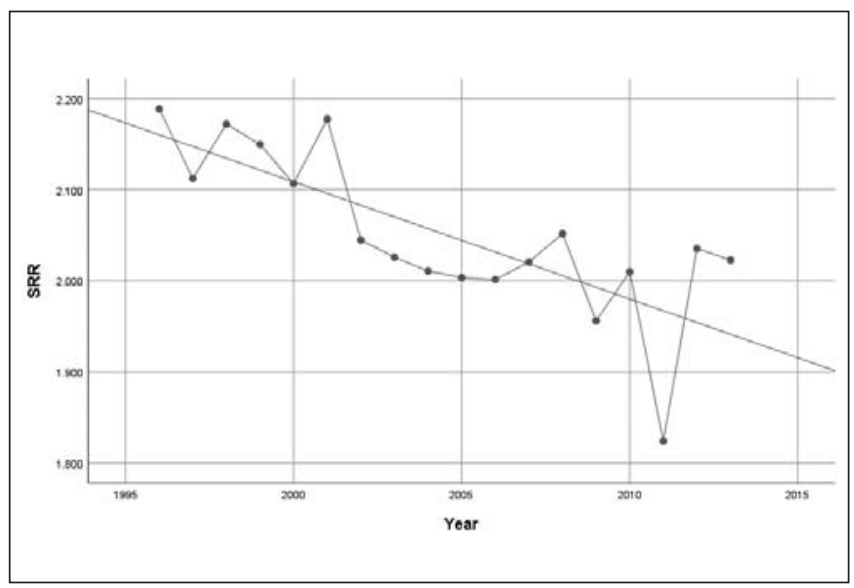

Fig. 4. Linear significant trend of standardised rate ratio in Chapter II and in Trenčín region.

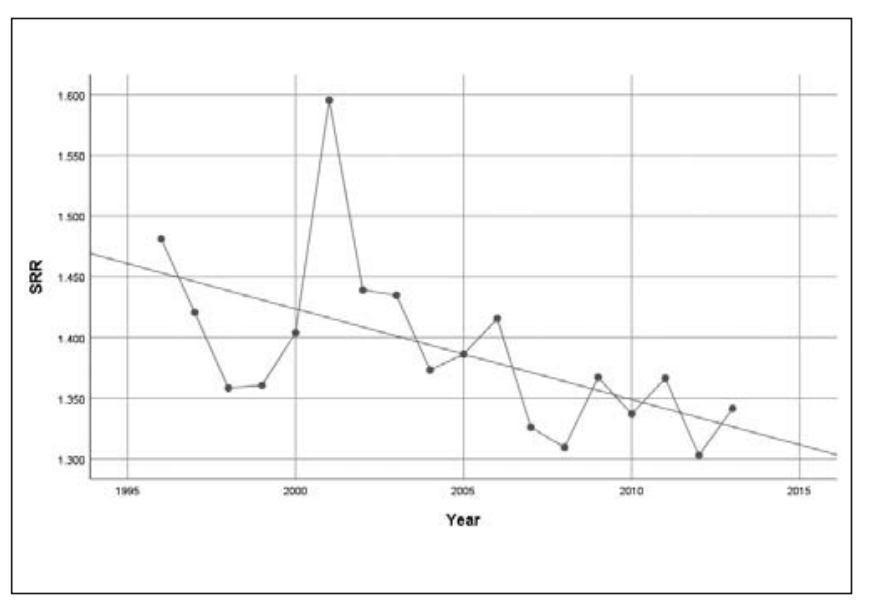

Fig. 5. Linear significant trend of standardised rate ratio in Chapter IX and in Žilina region.

In our analysis we want to emphasise the importance of regional prevention programs aiming at the most serious causes of deaths, circulatory system diseases and neoplasms, considering sex differences. Our findings about gender gap are consistent with the mentioned studies. Unfortunately, there are no active prevention programs in Slovakia at present. Attention should be paid to optimising the major factors of prevention, such as health nutrition as well as physical activity in relation to age, sex, employment and living conditions. Health is a key determinant of economic growth and development of the society. The central task is the cooperation with other players to create an environment that allows and encourages such changes in the behaviour of individuals, families and communities that are beneficial to health and will lead to a reduction in morbidity and mortality.

\section{CONCLUSIONS}

We have got interesting results of standardised rate ratio of age-adjusted mortality rates in group of men in comparison with group of women in Slovak regions in most frequent causes of death (Chapter II and Chapter IX).

Population studies are important but we must keep in mind also limits of such results because quite a few important determinants 
are not available. At individual level we can mention genetics, lifestyle, income, education and living conditions. At macro level there are other possible determinants e.g. environment, population composition, medical care disposal and medical care quality.

\section{Acknowledgements}

The work was supported by the VEGA Project No. 1/0945/17 Economic research on quantification of marketing processes aimed at improving value for patient, multidimensional analyses of the marketing mix of healthcare facilities and quantification of their importance in the process of establishment of the system to measure the quality and efficiency in healthcare of the Slovak Republic.

Dataset of individual cases of deaths in Slovakia with some demographic factors during 1996-2013 was kindly provided by Slovak National Health Information Center.

\section{Conflict of Interests}

None declared

\section{REFERENCES}

1. Mikkola TS, Gissler M, Merikukka M, Tuomikoski P, Ylikorkala O. Sex differences in age-related cardiovascular mortality. PloS One. 2013 May 20;8(5):e63347. doi: 10.1371/journal.pone.0063347.

2. Roth GA, Huffman MD, Moran AE, Feigin V, Mensah GA, Naghavi M, et al. Global and regional patterns in cardiovascular mortality from 1990 to 2013. Circulation. 2015;132(17):1667-78.

3. Naghavi M, Wang H, Lozano R, Davis A, Liang X, Zhou M, et al. Global, regional, and national age-sex specific all-cause and cause-specific mortality for 240 causes of death, 1990-2013: a systematic analysis for the Global Burden of Disease Study 2013. Lancet. 2015;385(9963):117-71.

4. Gupta R, Guptha S, Sharma KK, Gupta A, Deedwania P. Regional variations in cardiovascular risk factors in India: India heart watch. World J Cardiol. 2012;4(4):112-20.

5. Moran AE, Forouzanfar MH, Roth G, Mensah G, Ezzati M, Murray CJ, et al. Temporal trends in ischemic heart disease mortality in 21 world regions, 1980-2010: The Global Burden of Disease 2010 Study. Circulation. 2014;129(14):1483-92.

6. Davey Smith G, Gunnell D, Ben-Shlomo Y. Life-course approaches to socio-economic differentials in cause-specific mortality. In: Leon DA, Walt G, editors. Poverty, inequality and health: an international perspective. Oxford: Oxford University Press; 2001. p. 88-123.

7. Valkonen T. Socio-economic mortality differences in Europe. In: Beets GCN, van den Brekel JC, Cliquet RL, Dooghe G, de Jong Gierveld J, editors. Population and family in the low countries: late fertility and other current issues. NIDI CBGS publications, no. 30. Lisse: Swets \& Zeitlinger; 1994. p. 127-50.
8. Davletov K, McKee M, Berkinbayev S, Battakova Z, Vujnovic M, Rechel B. Regional differences in cardiovascular mortality in Kazakhstan: further evidence for the 'Russian mortality paradox'? Eur J Public Health. 2015;25(5):890-4.

9. Gavurová B, Vagašová T. Regional differences of standardised mortality rates for ischemic heart diseases in the Slovak Republic for the period 1996-2013 in the context of income inequality. Health Econ Rev. 2016;6:21. doi:10.1186/s13561-016-0099-1.

10. Gajdos O, Loncak V, Bartak M, Rogalewicz V. Cost of illness study of type 2 diabetes mellitus in the newly established diabetology outpatient facility in the Czech Republic. Value Health. 2015;18(7):A603-4.

11. Bartak M. The management of chronic diseases in international comparison. Vnitr Lek. 2014;60(5-6):462-6. (In Czech.)

12. Bulas J, Potočárová M, Murín J, Kozlíková K, Luha J, Čaprnda M. Central systolic hypertension in patients with well-controlled hypertension. Biomed Res Int. 2017;2017:8158974. doi: 10.1155/2017/8158974.

13. Ucieklak-Jeż P, Bem A, Predkiewicz P. Relationships between health care services and health system outcomes - empirical study on health system efficiency. In: Kajurová V, Krajíček J, editors. European financial systems 2015: Proceedings of the 12th International Scientific Conference on European Financial Systems; 2015 Jun 18-19; Brno, Czech Republic. Brno: Masaryk University; 2015. p. 633-40.

14. Bem A, Prędkiewicz P, Ucieklak-Jeż P, Siedlecki R. Profitability versus debt in hospital industry. In: Kajurová V, Krajíček J, editors. European financial systems 2015: Proceedings of the 12th International Scientific Conference on European Financial Systems; 2015 Jun 18-19; Brno, Czech Republic. Brno: Masaryk University; 2015. p. 20-7.

15. Popesko B, Papadaki Š, Novák P. Cost and reimbursement analysis of selected hospital diagnoses via activity based costing. E M Ekon Manag. 2015;18(3):50-61.

16. Bem A, Siedlecki R, Prędkiewicz, P, Ucieklak-Jeż P, Hajdikova T. Hospital's financial health assessment. Gradient method's application. In: Kapounek S, editor. Enterprise and competitive environment: Proceeding of the 18 Annual International Conference on Enterprise and Competitive Environment; 2015 Mar 5-6; Brno, Czech Republic. Brno: Mendel University in Brno; 2015. p. 76-85.

17. Barták M, Rogalewicz V, Jílková J, Jeřábková S. Cross-border healthcare in European Union and Czech Republic. Cas Lek Cesk. 2016;155(5):24753.

18. Siedlecki R, Bem A, Prędkiewicz, P, Ucieklak-Jeż P. Measures of hospital's financial condition - empirical study. In: Bratianu C, Zbuchea A, Pinzaru F, Vatamanescu EM, Leon RD, editors. Local versus global. Strategica: International Academic Conference; 2015 Oct 29-31; Bucharest. Bucharest: SNSPA; 2015. p. 666-75.

19. Fleiss JL, Levin B, Paik MC. Statistical methods for rates and proportions. New York: Wiley; 2004.

20. Newman SC. Biostatistical methods in epidemiology. New York: Wiley; 2001.

21. Huitema BE. The Analysis of covariance and alternatives. New York: Wiley; 2011. 